\section{Amyloidosis associated bleeding diatheses in the surgical patient}

Alan R. Mizutani MD, C.F. Ward MD

\begin{abstract}
The coagulopathies associated with amyloidosis have not been widely appreciated. We encountered a patient with amyloidosis and mildly abnormal coagulation studies who presented for an emergency laparotomy for acute bowel obstruction. Upon gentle manipulation of the bowel, an unexpected bleeding diathesis was manifested by the formation of several large haematomas resulting in a large amount of blood loss $1 \sim 800$ $m l)$. Numerous defects of platelet function and coagulation have been associated with amyloidosis, including abnormal platelet aggregation, increased vascular fragility, factor $I X$ and $X$ deficiencies, decreased levels of alpha-2-plasmin inhibitor, and increased levels of plasminogen. Intraoperative therapy for our patient included the rapid administration of four units of fresh frozen plasma and ten units of platelet concentrate. A review of the pathology and therapeutic modalities for this potemially life-threatening complication is presented.
\end{abstract}

On sous-estime souvent les problèmes de coagulation associés à l'amyloïdose. Un patient atteint de cette affection présenta une obstruction intestinale aiguë et on dut faire d'urgence une laparotomie malgré un coagulogramme légèrement anormal. Plusieurs gros hématomes se formèrent inopinément pendam la manipulation de l'intestin et totalisèrent une perte sanguine d'environ $800 \mathrm{ml}$. L'amyloïdose entraine une diathèse hémorragique à facettes multiples : agrégation plaquettaire anormale, fragilité vasculaire, déficit en facteur $I X, X$ et en inhibiteur de $l ' \alpha-2$-plasmine ainsi qu' un surplus de plaminogène. Nous avons donc traité notre patient en lui transfusant quatre unités de plasma frais congelé et dix unirés de concentré plaquetraire pendant l'opération. Dans notre arricle, nous révisons aussi la pathophysiologie et la thérapie de cente dangeretuse complication.

\section{Key words}

BLOOD: coagulation;

COMPLICATIONS: amyloidosis;

HAEMORRHAGE; coagulopathy.

From the Department of Anesthesiology, University of California, San Diego Medical Center, San Diego CA 92103.

Address correspondence 10: Dr. A.R. Mizutani, Department of Anesthesiology, UCSD Medical Center, 225 Dickinson Street, San Diego CA 92103.
Amyloidosis is a progressive multisystem disease of abnormal extracellular amyloid protein deposition within a number of sites including the kidneys, liver, heart, lungs, gastrointestinal tract, skin, nervous system, and joints. 'The anaesthetic considerations regarding the airway, cardiac, and renal manifestations of the illness have been described. ${ }^{2}$ We describe a case of a patient with a bleeding diathesis associated with amyloidosis, a potentially life-threatening manifestation which has not been previously reported in the anaesthesia literature.

\section{Case history}

A 48-yr-old white female with an acute small bowel obstruction presented for an emergency exploratory laparotomy. Amyloidosis had been diagnosed three years earlier. She had experienced one episode of right heart failure which was judged to be secondary to cardiac amyloidosis with decreased right ventricular function. This was treated with chronic diuretic therapy (furosemide $80 \mathrm{mg} \cdot$ day $^{-1}$ ). Additionally, she was in chronic atrial fibrillation controlled with digoxin $(0.25 \mathrm{mg}$. day $^{-1}$ ). The patient had not experienced clinical left ventricular failure. A second complication of her amyloidosis involved chronic airway obstruction from macroglossia which one year previously had required a tracheostomy. By history and recent evaluation, there was no detectable pulmonary, renal, hepatic, articular, gastrointestinal, or neurological involvement from anyloidosis. She denied any symptoms of bleeding and indicated that her family history was unremarkable for any bleeding disorders. She denied the use of any non-steroidal anti-inflammatory drugs. Physical examination of the patient revealed an obese $(75 \mathrm{~kg}, 173 \mathrm{~cm})$ woman with a large protruding tongue (which occluded the oral cavity), an intact and functioning \#5 metal tracheostomy tube, and an irregular heart rhythm.

Laboratory values for electrolytes, haemoglobin, and haematocrit were all within normal limits. Platelet count was $355,000 \cdot \mathrm{mm}^{-3}$, prothrombin time (PT) was $13.1 \mathrm{sec}$ (control $=12.1 \mathrm{sec}$ ), and partial thromboplastin time (PTT) was $33.5 \mathrm{sec}$ (control $=27.1 \mathrm{sec})$. Bleeding time was found to be mildly prolonged at $13 \mathrm{~min}$ (normal $<10$ $\mathrm{min}$ ). Electrocardiogram revealed atrial fibrillation with a ventricular response of 70 beats per minute and was 
otherwise notable for non-specific ST and $\mathrm{T}$ wave changes. Chest $x$-ray showed decreased lung volumes and mild cardiomegaly, but was otherwise normal.

Prior to induction of anaesthesia, radial artery and pulmonary artery catheters were placed. After control of the airway by placement of a tracheal tube within the tracheostomy, anaesthesia was induced slowly and uneventfully with alfentanil $100 \mu \mathrm{g} \cdot \mathrm{kg}^{-1}$ and thiamylal 100 $\mathrm{mg}$ in divided doses, and vecuronium $0.1 \mathrm{mg} \cdot \mathrm{kg}^{-1}$. Anaesthesia was maintained with oxygen, alfentanil infusion $1.0 \mu \mathrm{g} \cdot \mathrm{kg}^{-1} \cdot \mathrm{min}^{-1}$, and isoflurane $0.4-2.0 \mathrm{per}$ cent inspired concentration.

On incision, a moderate amount of bleeding occurred which was controlled by extensive electrocautery. With minimal gentle manipulation of the bowel and mesentery, the surgeon noted the rapid formation of several large $100-200 \mathrm{ml}$ hacmatomas. Coagulation studies were repeated immediately and a consultation with a haematologist was obtained. Platelet count, PT, and PTT were unchanged from the preoperative values. Thrombin time (TT) and fibrin degradation product assays (FDP) were normal. Ten units of platelet concentrate and four units of fresh frozen plasma were rapidly crossmatched and administered. Subsequently, haematoma formation halted. No additional blood products were administered and the estimated blood loss was $800 \mathrm{ml}$. The mesenteric adhesions were lysed, the abdomen was closed, and the patient was taken to the post-anaesthesia care unit where emergence was unremarkable. Pretransfusion, intraoperative haematological studies revealed factor IX and $X$ assays of 70 per cent.

Four months after the procedure, a full haematological workup revealed normal levels of factors $\mathrm{IX}, \mathrm{X}$, and alpha-2-antiplasmin. Assays of factor VIII (240 per cent, normal $=60-150$ per cent $)$, Von Willebrand antigen (280 per cent, normal $=60-150$ per cent), and ristocetin cofactor (196 per cent, normal $=60-150$ per cent) exceeded normal levels. In vitro platelet aggregation studies (ADP, epinephrine, ristocetin, and connective tissue) were all normal. No additional blood products had been administered since the surgery. In an interview at that time, the patient stated that she had noted symptoms of easy bruising and difficulty with haemostasis after venipuncture.

\section{Discussion}

The clinical bleeding manifested in these patients may be secondary to any of three basic defects in haemostasis. These defects may involve abnormalities of platelet function, increased vascular fragility, and multifactorial defects in coagulation and fibrinolysis. Platelet dysfunction has been described as an isolated defect. ${ }^{3}$ While platelet aggregation in vitro as well as platelet quantity appear normal, a defect seems to lie in the interaction between the platelets and the connective tissue substrate; $;^{3}$ however, the aetiology of this altered interaction has yet to be elucidated. Symptoms sometimes associated with this non-thrombocytopenic purpura include ecchymoses which may occur in both normal skin and in skin that shows evidence of amyloid infiltration. The most common and characteristic site of involvement is the eyelids; bruising may occur spontaneously or with such minor trauma as rubbing of the eyelids. Other commonly affected areas may include the remainder of the face, the neck, the axillary folds, and the oral and anogenital mucosae. $^{4}$

Vascular fragility may be increased in these patients and is presumed to be secondary to vascular infiltration with amyloid. ${ }^{5}$ Microangiopathic haemolysis may also occur leading to fibrinolysis and intravascular coagulation. ${ }^{6}$ Quantitative abnormalities in factors $\mathrm{IX}$ and $\mathrm{X}$ as well as alterations in plasma antithrombin activity have been noted. In a series of 95 patients with amyloidosis, Greipp et al. found a six per cent incidence of isolated factor $X$ deficiency. The bleeding symptoms in many of these patients far exceeded estimations made solely on the basis of the factor activity assays, ${ }^{7}$ suggestive of functional abnormalities in addition to quantitative deficiencies. The aetiology of the factor $X$ deficiency has been attributed to the direct binding and sequestration of factor $\mathrm{X}$ by amyloid fibrils exposed to circulating blood. Studies have supported this mechanism not only for factor $X$ but for factor IX and prothrombin as well. In experiments performed by Furie et al, isolated amyloid fibrils were found to bind avidly to radiolabeled factor X. Over 80 per cent of infused factor $X$ was removed from the intravascular compartment with an elimination half-time of less than $30 \mathrm{sec}$ (90 min in controls). ${ }^{8}$ It is thought that much of the exposure of circulating blood to the amyloid fibrils occurs within the spleen and other components of the reticuloendothelial system. This is supported by the finding that factor $\mathrm{X}$ deficiency in these patients may be resolved by splenectomy. ${ }^{9}$

Decreased alpha-2 plasmin inhibitor, increased plasminogen, and elevated concentrations of tissue plasminogen activator have also been noted. ${ }^{10}$ This suggests that excessive fibrinolysis may be the aetiology of bleeding abnormalities in many of these patients. It has been hypothesized that the breakdown of plasminogen activator may be delayed due to lack of clearance in the liver secondary to hepatic amyloidosis resulting in a hyperfibrinolytic state. Another possibility is the continuous release of pathologically high levels of tissue plasminogen activator." An additional potential contributing factor in the deficiency of coagulation factors is the involvement of the liver with amyloid infiltration, but this 
usually only occurs with severe liver disease and is usually apparent from other evidence of abnormalities of hepatic synthetic function. Abnormalities of coagulation should be suspected in patients with amyloidosis. Any history of unusual bleeding or bruising should be carefully noted. Routine laboratory evaluation should include PT, PTT, TT, bleeding time, fibrinogen, and FDP titers.

Our patient had only a mildly prolonged PT and PTT and gave a preoperative history that was unremarkable for previous bleeding problems. With the exception of the prolonged bleeding time, other in vitro assays of coagulation factors and platelet function were normal. We speculate that the major defects leading to the haematoma formation observed involved isolated abnormal plateletvessel wall interaction. As noted by Malpass and Harker, ${ }^{3}$ patients with this problem may exhibit no evidence of an intrinsic platelet defect. As well, capillary fragility may have also played a role in the intraoperative event. Von Willebrand factor and antigen as well as ristocetin tests showed no deficits, ruling out Von Willebrand's disease. Factor VII, IX and X assays revealed levels that should have been adequate for normal haemostasis. Intraoperative assays for TT and FDP were normal, making the diagnosis of intravascular fibrinolysis unlikely.

For those patients that have a known factor $X$ deficien$c y$, it has been recommended that factor $\mathrm{X}$ be provided prior to the procedure by infusion of two to three units of prothrombin complex concentrate or FFP. ${ }^{12}$ It is important that the infusion be given prior to surgery due to the relatively short half-life of factor $X$. Factor IX deficiency may be replaced with factor IX concentrate or FFP administered prior to the start of the procedure. Clinically inadequate responses may require further treatment with additional units of FFP. Pretreatment with vitamin K often provides no benefit to these patients except in the patient with liver disease, malabsorption, poor nutrition, or antibiotic therapy. ${ }^{6,13,14}$ Therapy with steroids (prednisone) may be beneficial, although the mechanism of action is unknown. In patients with evidence of hyperfibrinolysis and high levels of tissue plasminogen activator, intravenous epsilon amino caproic acid has been recommended and found to be clinically useful in patients with active bleeding. ${ }^{11,15}$

Therapy in our patient consisted of infusion of platelets as well as FFP. Platelet concentrates may be helpful in cases where platelet-vessel wall interactions seem to be at fault. There are no data regarding the role of DDAVP (desmopressin) therapy with respect to the improvement of platelet function in patients with amyloidosis.

The coagulopathies associated with amyloidosis have not been widely appreciated. They should, however, be an additional anaesthetic consideration when a patient with this disease is encountered. A careful history, examination, and laboratory evaluation coupled with a high index of suspicion may help the clinician prepare for and avoid the complications of unexpected haemorrhage.

\section{References}

I Cohen AS. Amyloidosis. In: Braunwald E, Isselbacher KJ, Petersdorf RG et al. (Eds.). Harrison's Principles of Internal Medicine, I lih ed. New York: McGrawHill Book Co, 1987; 1403.

2 Roesch RP. The Immune System. In: Stoelting RK, Dierdorf SF (Eds.). Anesthesia and Coexisting Disease. New York: Churchill Livingstone, 1983; 657.

3 Malpass TW, Harker LA. Acquired disorders of platelet function. Semin Hematol 1980; 17: 242-58.

4 Brownstein $M H$, Helwig EB. The cutaneous amyloidoses: II. Systemic forms. Arch Dermatol 1970; 102: 20-8.

5 Kyle RA, Bayrd ED. Amyloidosis: review of 236 cases. Medicine (Baltimore) 1975; 54: 271-99.

6 Bowie EJW, Maldonado JE, Brown AL, Didisheim P. Owen $C A$. Intravascular coagulation in systemic amyloidosis. Thrombosis et Diathesis Haemorrhagica [Suppl] 1969: 36: 305

7 Greipp PR, Kyle RA, Bowie EJW. Factor-X deficiency in amyloidosis: a critical review. Am J Hematol 1981; 11: 443-50.

8 Furie B, Voo L, McAdam KPW, Furie BC. Mechanism of factor $\mathrm{X}$ deficiency in systemic amyloidosis. $N$ Engl J Med 1981; 304: 827-30.

9 Greipp PR, Kyle RA, Bowie EJW. Factor X deficiency in primary amyloidosis: resolution after splenectomy. $\mathrm{N}$ Engl J Med 1979; 301:1050-1.

10 Takahashi H, Koike T, Yoshida $N$ et al. Excessive fibrinolysis in suspected amyloidosis: demonstration of plasmin $\alpha-2$ plasmin inhibitor complex and von Willebrand factor fragment in plasma. Am J Hematol 1986; 23: 153-66.

11 Chang JC, Kane $K K$. Pathologic hyperfibrinolysis associated with amyloidosis: clinical response to epsilon amino caproic acid. Am J Clin Pathol 1984; 81 : 382-7.

12 Spero JA, Lewis JH, Hasiba U, Ellis LD. Treatment of amyloidosis assosciated factor $X$ deficiency. Thromb Haemost 1976; 35: 377-81.

13 Pechet L, Kastrul JJ. Amyloidosis associated factor $X$ deficiency: case report. Ann Intern Med 1964; 6I: 315-8.

14 McPherson RA, Onstad JW, Ugoretz RJ, Wolf PL. Coagulopathy in amyloidosis: combined deficiency of factors IX and X. Am J Hematol 1977; 3: 225-35.

15 Millard LG, Rowell NR. Primary amyloidosis and myelomatosis associated with excessive fibrinolytic activity. Br J Dermatol 1976; 94: 569-7I. 